\title{
Adherence to Antiretroviral Therapy among Adult Persons Living with HIV/AIDS in Southern Ethiopia
}

\section{Hailu Chare Koyra*}

Department of Pharmacy, College of Medicine and Health Sciences, Wolaita Sodo University, Ethiopia

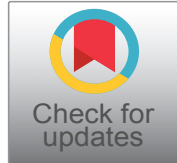

*Corresponding author: Hailu Chare Koyra, Department of Pharmacy, College of Medicine and Health Sciences, Wolaita Sodo University, P.O. Box 138, Soddo, Ethiopia, Tel: +251-913446310/+251-982067288, E-mail: charehailu@gmail.com;

hailu.chare@wsu.edu.et

\begin{abstract}
Background: Unlike other chronic diseases, people receiving anti-retroviral treatment should have very high levels of adherence $(\geq 95 \%)$ to achieve durable suppression of viral load; avoid the emergence of drug resistance and clinical failure. Therefore, this study was aimed to assess level of adherence and predictors of poor adherence among adult ART patients at Dubbo St. Marry Hospital, Southern Ethiopia.
\end{abstract}

Method: A facility based cross sectional study was conducted to collect data by using structured questionnaires and Moriky's Medication adherence method. Both binary and multiple logistic analyses were performed to examine the influences of different variables on adherence and controlling for potential confounders.

Results: Out of 320 patients participated in the study, 214 [64\%] were females and 162 [48.5\%] found within the age range of $36-45$ years. Among the patients, $32 \%$ had poor adherence and comorbidity $[A O R=4.004,95 \% \mathrm{Cl}=2.104$, 10.830], substance use $[A O R=2.360,95 \% \mathrm{Cl}=4.347$, 17.915], living alone $[A O R=2.262,95 \% \mathrm{Cl}=1.083,5.521]$ type of regimen $[A O R=0.262,95 \% \mathrm{Cl}=0.083,0.521]$, self-stigma $[A O R=2.922,95 \% \mathrm{Cl}=2.446,10.901]$ and poly-pharmacy $[A O R=4.022,95 \% \mathrm{Cl}=1.665,9.730]$ independently predicted poor adherence.

Conclusion: Level of medication adherence (68\%) among ART patients at Dubbo St. Marry hospital was found to be suboptimal. The major reasons for not adhering to treatment were forgetting to take medications and fear of adverse effects.

\section{Keywords}

Adherence, Antiretroviral therapy, Hospital, Ethiopia

\begin{abstract}
Abbreviations
AIDS: Acquired Immune Deficiency Syndrome; ART: Antiretroviral Therapy; ARV: Antiretroviral; CD4: Cluster of Differentiation; DOT: Directly Observed Therapy; EFMOH: Ethiopian Federal Ministry of Health; HAART: Highly Active Antiretroviral Therapy; HAPCO: HIVIAIDS Prevention and Control Office; HIV: Human Immune Deficiency Virus; MMAS: Morisky Medication Adherence Scale; OI: Opportunistic Infection; PEPFAR: US President's Emergency Plan for AIDS Relief; PLWHA: People Living with HIVIAIDS; TM: Traditional Medicine; USA: United State of America; WHO: World Health Organization
\end{abstract}

\section{Introduction}

The human immunodeficiency virus (HIV) is a retrovirus that infects cells of the immune system, destroying or impairing their functionality. As the infection progresses, the immune system of the infected person becomes weaker, and the patient becomes more susceptible to contract opportunistic diseases. The most advanced stage of HIV infection is acquired immunodeficiency syndrome (AIDS). HIV/AIDS is a public health problem and major development crisis that affects all sectors. It has drastically affected health, economic and social progress reducing life expectancy, deepening poverty, and contributing to and exacerbating food shortages. Today, the estimated number of individuals living with HIV/AIDS worldwide is approximately 33.4 million, including 2.1 million children. The new infection rate is approximately 2.7 million per year, including 430,000 children. Globally, the highest level of HIV/AIDS cases is in sub-Sahara Africa, where approximately 22.4 million peoples are infected $[1,2]$.

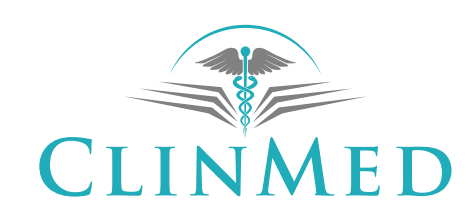

INTERNATIONAL LIBRARY
Citation: Koyra HC (2018) Adherence to Antiretroviral Therapy among Adult Persons Living with HIV/ AIDS in Southern Ethiopia. Int J Virol AIDS 5:038. doi.org/10.23937/2469-567X/1510038 Received: January 06, 2018: Accepted: May 12, 2018: Published: May 14, 2018

Copyright: (C) 2018 Koyra HC. This is an open-access article distributed under the terms of the Creative Commons Attribution License, which permits unrestricted use, distribution, and reproduction in any medium, provided the original author and source are credited. 
Ethiopia is among the countries most affected by HIV epidemic with an estimated 790,000 HIV positive people. According to the Ethiopian demographic survey, adult HIV prevalence in 2011 was estimated to be 1.5\%. In addition, children under 15 -years are also heavily affected and account for over 20\% living with HIV in 2011 with prevalence in the urban and rural population $7.7 \%$ and $0.9 \%$ respectively. In the country, ART was first offered in July 2003 through 12 government hospitals on a co-payment basis. In early 2005, 211,000 men, women and children needed ART but only 16,400 were receiving it $[3,4]$.

Adherence is taking the correct dose of medications, on schedule, and following dietary instructions. Unlike other chronic conditions, very high levels of adherence (> 95\%) are required for ART to be effective for long term and to prevent the emergence of resistant viral strains. Poor adherence is linked to the development of drug resistance, higher mortality rates, lower rates of increase in CD4 cell count, lower rates of undetectable viral load, lower therapeutic success and increased hospital days $[5,6]$.

The importance of ART is that it shortens illness duration, improves quality of life and survival of PLWHA through reduction of viral load and increasing the level of CD4 cells. However, lack of adherence to ART is a major challenge to AIDS care [7].

\section{The conceptual frame work}

The conceptual framework of this study is based on literature findings that showed factors which have been cited as reasons for non-adherence include forgetting, travel, fear of disclosure, shortage of pills, difficult schedules, lack of access and privacy (Figure 1). Other consistent factors for poor adherence include patient reported symptoms, stress, lack of social support, substance use, regimen complexity, self-efficacy for medication taking and depression [8].

\section{Significance of the study}

Little is known about the factors affecting ART adherence and the magnitude of ART adherence in Wolaita Zone, especially Areka town. Therefore, the objective of this study is to assess level of adherence and predictors of poor adherence among HIV/AIDS patients receiving Antiretroviral Therapy at Dubbo St. Marry Hospital.

The issue of ARV adherence among HIV/AIDS in Ethiopia and in study area is important. This study determined the status and magnitude of adherence and factors that affect adherence in Dubbo St. Marry hospital among patients who follow ARV therapy. Since there is no previous research conducted on this title in the study area, the finding of this study is important for policy makers, and will be used as a baseline data for future research. In addition, this study will create the awareness in society about ARV adherence.

\section{Methodology}

\section{Study area and period}

The study was conducted in Dubbo St. Marry Hospital, Areka town, SNNPR, Ethiopia. Areka town is located about 382 km south from Addis Ababa, about 205

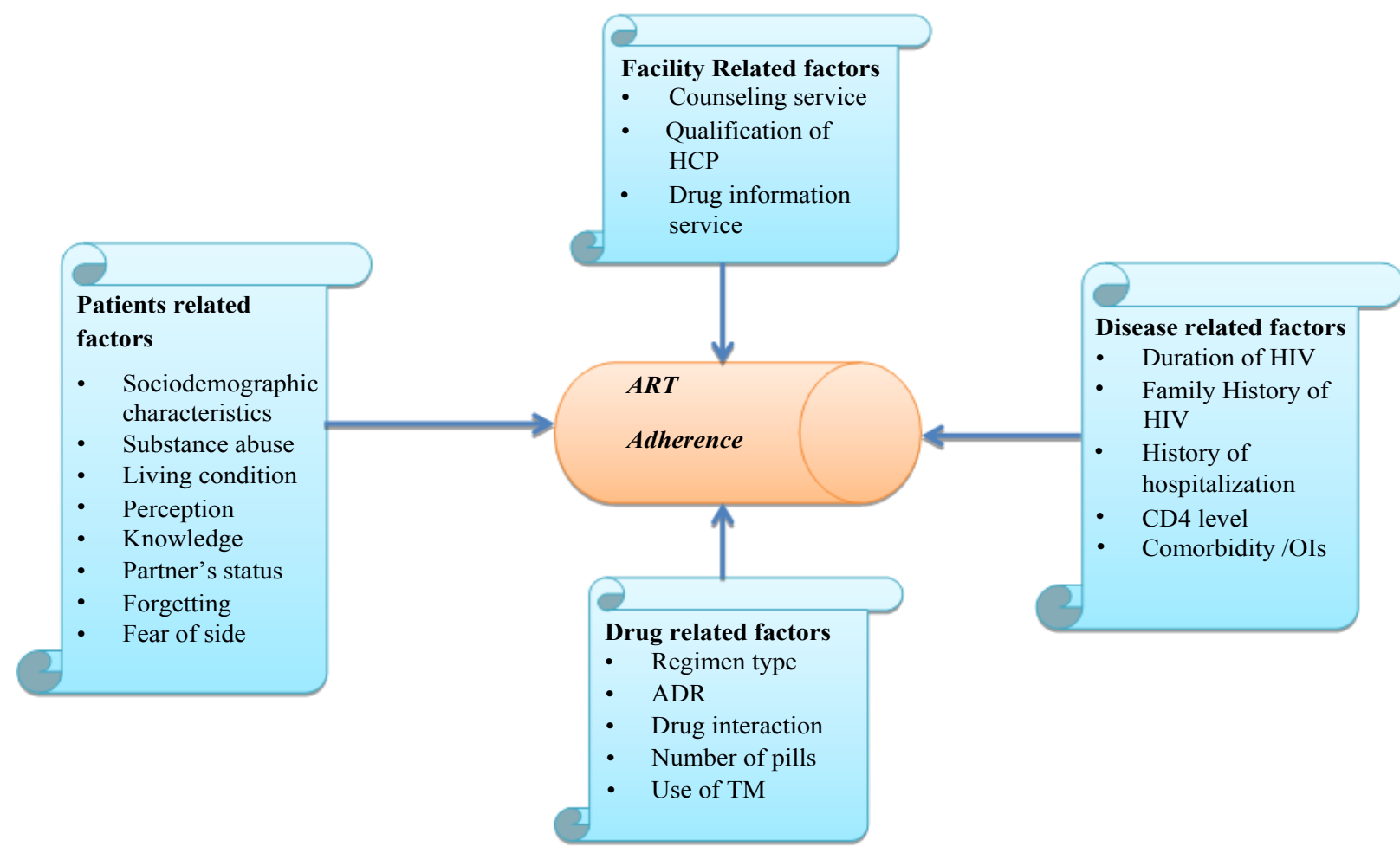

Figure 1: Conceptual frame work of ART adherence and predictors of poor adherence among HIVIAIDS patients at Dubbo St. Marry Hospital Southern, Ethiopia, 2014. 


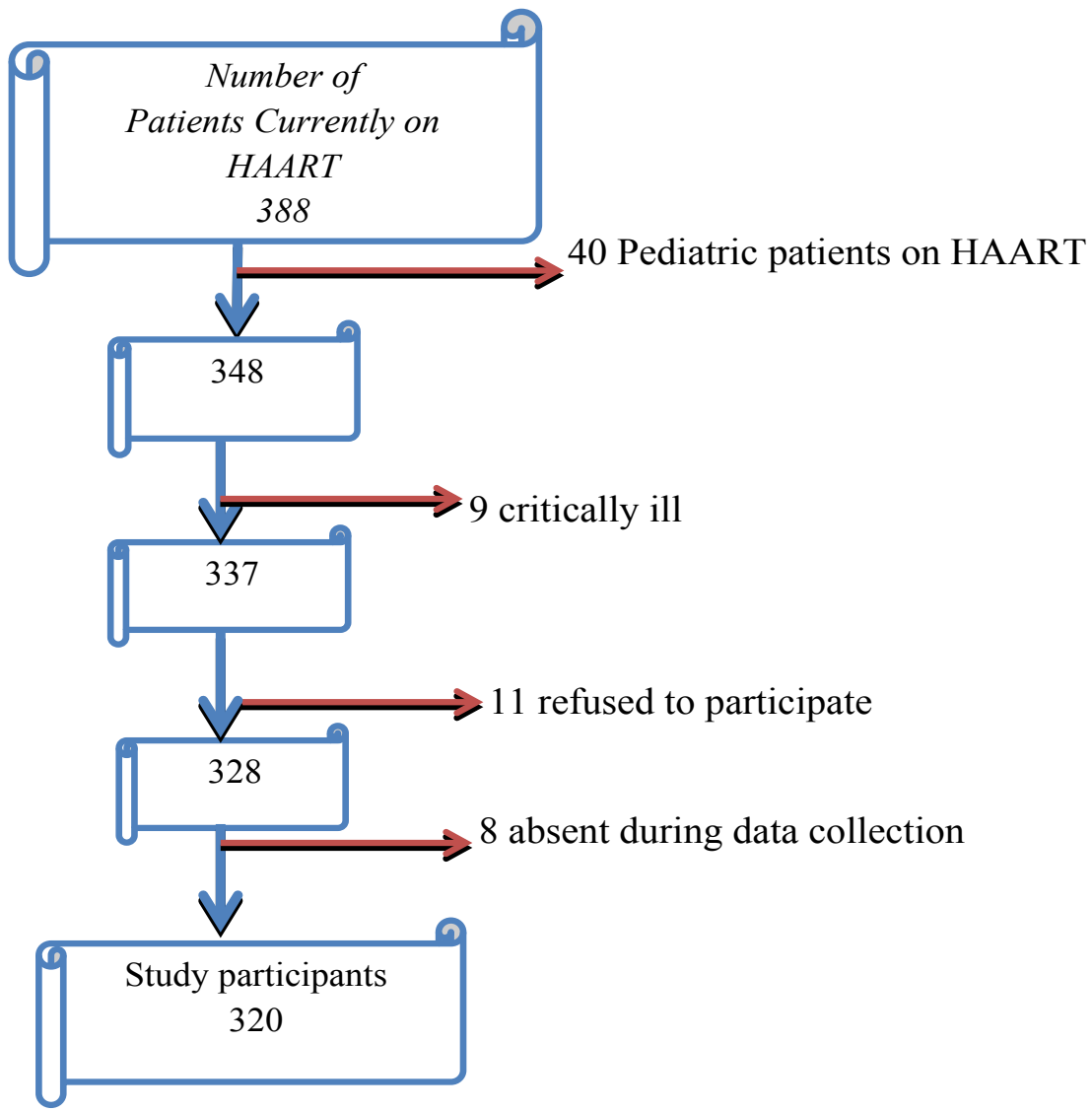

Figure 2: Schematic representation of sampling procedure during the period of data collection.

$\mathrm{km}$ from Hawassa, the capital of the SNNPR region. The hospital is rapidly expanding in terms of services it provides and infrastructures. It provides multidimensional aspects of care to clients who need health service. There are 6 specialty units and many follow-up services for both pediatric and adult patients. The study was conducted from July to August 2016.

Study design: An institutional based cross sectional descriptive study was conducted.

Study population: Patients on ART during the study period and who fulfill inclusion criteria.

Inclusion criteria for interviewees: Age above 18 years and those on ARV treatment for at least 3 months or more.

Exclusion criteria: Critically ill, unwilling and patients with documented mental illness.

Sample size and sampling technique: The study was designed to collect data from all adult patients who were on their chronic care follow up, and willing to participate in the study as depicted in the Figure 2.

\section{Study variables}

$\checkmark$ Medication adherence to ART, Socio-demographic, Socio-cultural factors, Disease related variables, Medication and facility related variables, Patients related variables.

Data collection technique: Data was collected through structured questionnaire which was translated to the local language for patient interview to collect informa- tion on socio-demographic, socio-economic and information on medication adherence.

Data process and analysis: Completeness of the data was checked every day and entered and cleaned using EPI-data version 3.1 and exported to SPSS. To examine the influences of different variables on medication adherence and controlling for potential confounders, both binary and multiple logistic analyses were performed. Independent variables having $p$-value $<0.25$ in the bivariate logistic regression analysis were entered into multivariable logistic regression analysis in order to control confounding effect. P-value of $<0.05 \%$ was considered significant in the final model.

Medication adherence assessment tool: Non-adherence was identified by using validated Morisky Medication Adherence Scale (MMAS) which consists of 8 items with a dichotomous response (yes/no) with questions asking the patient to respond "yes" or "no" to items 1-7 and a 5 point Likert response for the last item. A positive response indicates a problem with adherence. Therefore, higher scores indicate that a patient is least-adherent to medications. The total score for each patient is the summation of the scores in each item [9].

Ethical considerations: After obtaining approval of Ethical Review Board (ERB) of the College, an official letter of was sent to the hospital for study cooperation. Data was collected after permission was taken from the study subjects following a brief discussion with the patients on ART about the purpose and public health 
importance of the study. Data was collected only from those who were willing to participate. To maintain confidentiality, all respondents' data were anonymised.

\section{Results}

\section{Socio-demographic and socio-economic characteris- tics}

Table 1: Basic socio-demographic attributes of HIVIAIDS patients at Dubbo St. Marry Hospital 2016.

\begin{tabular}{|c|c|c|}
\hline Variables & Frequency & Percent \\
\hline \multicolumn{3}{|l|}{ Ethnicity of respondents } \\
\hline Wolaita & 162 & 50.6 \\
\hline Hadiya & 68 & 21.3 \\
\hline Kambata & 50 & 15.6 \\
\hline Others & 40 & 12.5 \\
\hline \multicolumn{3}{|l|}{ Educational status } \\
\hline Illiterate & 16 & 5 \\
\hline Grade 1-8 & 160 & 50 \\
\hline Grade 9-12 & 32 & 10 \\
\hline Diploma and above & 112 & 35 \\
\hline \multicolumn{3}{|l|}{ Marital status } \\
\hline Single & 24 & 7.5 \\
\hline Married & 184 & 57.5 \\
\hline Divorced & 56 & 17.5 \\
\hline Widowed & 40 & 12.5 \\
\hline Separated (not confirmed legally) & 16 & 5.0 \\
\hline \multicolumn{3}{|l|}{ Occupational status } \\
\hline Government employee & 110 & 34.4 \\
\hline Merchant & 70 & 22 \\
\hline Driver & 36 & 11.2 \\
\hline Farmers & 60 & 18.7 \\
\hline Police men & 20 & 6.2 \\
\hline Others & 24 & 7.5 \\
\hline \multicolumn{3}{|l|}{ Sex } \\
\hline Female & 214 & 67 \\
\hline Male & 106 & 33 \\
\hline \multicolumn{3}{|l|}{ Place of residence } \\
\hline Urban & 122 & 38.2 \\
\hline Rural & 188 & 61.8 \\
\hline \multicolumn{3}{|l|}{ Monthly income } \\
\hline Below 500 & 70 & 21.8 \\
\hline $500-1000$ & 58 & 18.4 \\
\hline $1000-1500$ & 142 & 44.2 \\
\hline Above 1500 & 50 & 15.6 \\
\hline \multicolumn{3}{|l|}{ Age of respondents } \\
\hline $18-25$ & 14 & 4.4 \\
\hline $26-35$ & 104 & 32.5 \\
\hline $36-45$ & 162 & 50.6 \\
\hline Above 45 & 40 & 12.5 \\
\hline \multicolumn{3}{|l|}{ Living condition } \\
\hline Alone & 128 & 40 \\
\hline With family & 120 & 37.5 \\
\hline College/university & 32 & 10 \\
\hline Support centers & 18 & 5.5 \\
\hline Other $^{*}$ & 22 & 7 \\
\hline
\end{tabular}

"Military camp, prisoner.
Among 348 adult persons on ART, 320 participated in the final study (Figure 2). Out of this, 214 [67\%] females and 106 [33\%] males participated in this study. From the respondents, 184 [57.5\%] were married; and 162 [50.6\%], 68 [21.25\%], 50 [15.6\%], of them were Wolaita, Hadiya, and Kambata, by ethnicity respectively. As to the religion of respondents, 150 [46.9\%], 110 [33.4\%] and 60 [18.7\%], were Protestant, Orthodox and Muslim, respectively.

The majority of the participants had primary school complete $85.0 \%$ followed by holders of diploma and above $35.0 \%$. As to occupation of the participants, majority of ART patients were found to be government employee 110 (34.4\%) and merchants 70 (22\%).

Of the respondents, majority were found within the age range of $36-45$ years, 162 [50.6\%] followed by age range of $26-35,104$ [32.5\%].

As to the living conditions of respondents, majority reported as they either live alone or together with their family, $128(40 \%)$ and $120(37.5)$ respectively (Table 1$)$. It was also found that majority of respondents stayed 6-10 years, 112 (35\%) followed by 1-5 years $68(21.3 \%)$ since they started their ART (Table 2).

Only $30(18.7 \%)$ of the respondents reported that they did not suffer from stigma due to their HIV status. But, majority $78(48.7 \%)$ of respondents said that they avoid friends or relatives due to stigma during ARV treatment. Surprisingly, 113 (70.7\%) of respondents reported that they use traditional methods of treatment in addition to HAART. Among respondents, 106 (66.2\%) reported as they perceive HAART is effective to reduce their viral load and improve life.

Among the respondents, about $10 \%$ reported that their sex-partners were sero-negative (discordant) and $8.2 \%$ have not known their status yet. Majority, 135 (84.4\%) of ART patients reported that they do not know about adverse effects of ARV drugs (Table 2).

As depicted in the Figure 3, this study also collected data on substance abuse and found that over all prevalence of substance use was found to be 69 (43\%). Among these, majority 55 (79.7\%) reported that they were using both alcohol and cigarette followed by drinking alcohol only $41(59.4 \%)$ to relieve pain and depression associated with the disease (Figure 3 ).

More than half, 182 (56.8\%) of the respondents, were with documented comorbidities. Among those, it was found that the most common disease conditions other than HIV were TB $28.5 \%$, fungal infections $21 \%$ and depression $17.5 \%$ (Table 3).

\section{Medication adherence and perceived reasons for poor adherence (based on MMAS-8)}

According to MMAS, 218 (68\%) of respondents had good medication adherence (MMAS < 3) and $102(32 \%)$ 


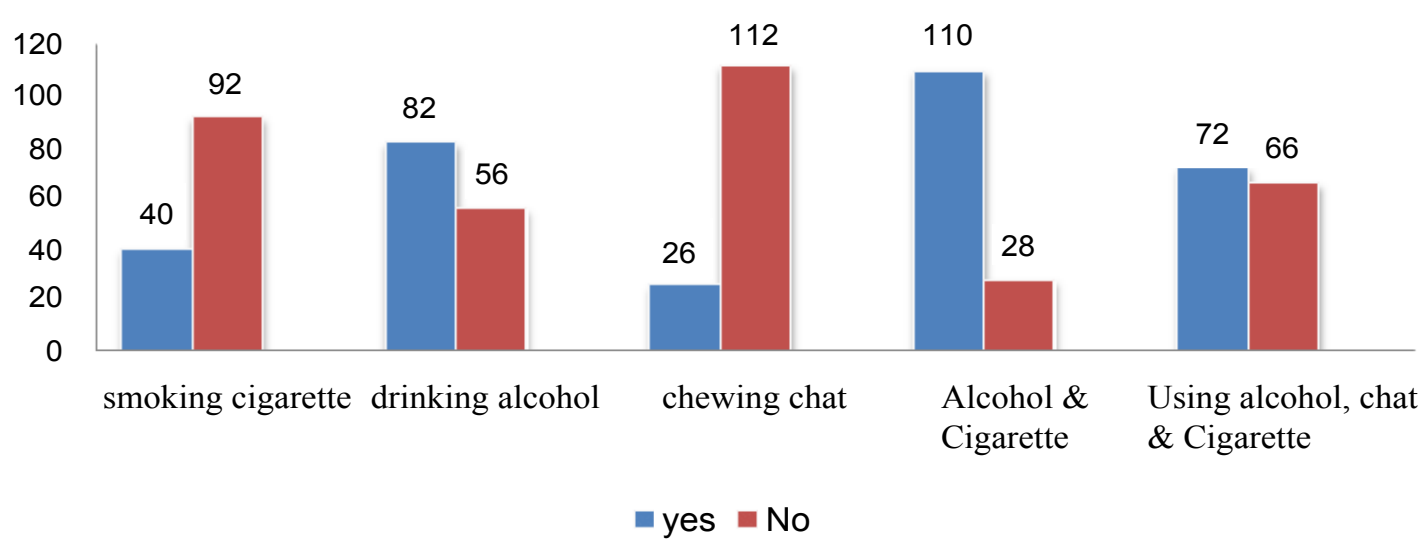

Figure 3: Prevalence of substance abuse among study participants, Dubbo St. Marry Hospital, Southern Ethiopia, 2016, $N=320$.

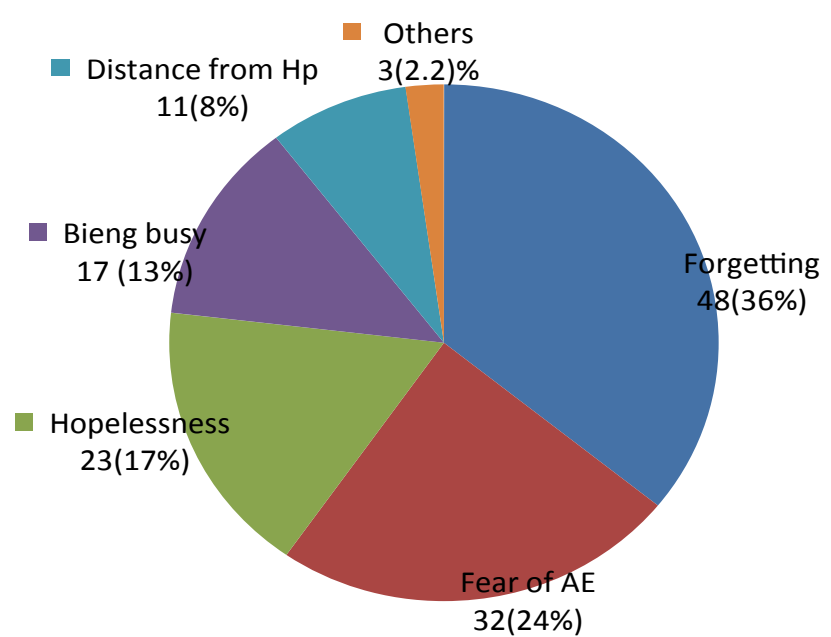

Figure 4: Perceived reasons for poor-adherence reported by HIVIAIDS patients at Dubbo St. Marry Hospital, Southern Ethiopia, $2016(\mathrm{~N}=102)$.

found to have poor medication adherence (MMAS $\geq$ 3). The patients were also asked to mention reasons or barriers for not-adhering to ARV drugs. The major reasons for not adhering to treatment were forgetting to take medications 44 (43\%) followed by fear of adverse effects 30 (29\%) (Figure 4).

\section{Health care facility and health care providers in- fluence on adherence to ARV treatment.}

All of respondents [100\%] said that they were able to follow their ARV treatment, they know the importance of following the course of treatment strictly, they were counseled especially before they were started on ARV treatment, privacy was maintained during consultations and agreed that it was important for HIV-patients to be counseled as they continue with ARV treatment because it helped to improve ART adherence. However, majority of respondents $84.4 \%$ did not know about the side effects and interactions of ARV drugs (Table 2).

As depicted above, distributions of ART drug regimens used by the HIV/AIDs patients at Dubbo St. Marry Hospital, more than $56 \%$ of the participants were tak-
Table 2: Disease and patients related variables among HIV/ AIDS patients at Dubbo St. Marry Hospital, Southern Ethiopia, $2016(\mathrm{~N}=320)$.

\begin{tabular}{|c|c|c|}
\hline Variables & Frequency & Percent \\
\hline \multicolumn{3}{|c|}{ Duration of ART (length of time of ART in years) } \\
\hline Below one year & 40 & 12.5 \\
\hline $1-5$ years & 68 & 21.3 \\
\hline $6-10$ years & 112 & 35 \\
\hline $11-15$ years & 56 & 17.5 \\
\hline Above 15 years & 44 & 13.7 \\
\hline \multicolumn{3}{|c|}{ Sero-status of sex partner } \\
\hline Positive & 260 & 81.2 \\
\hline Negative & 34 & 10.6 \\
\hline Not known & 26 & 8.2 \\
\hline \multicolumn{3}{|c|}{ Previous history of hospitalization after ART } \\
\hline Yes & 104 & 32.5 \\
\hline No & 216 & 67.5 \\
\hline \multicolumn{3}{|c|}{ Experiencing stigma } \\
\hline From others & 156 & 48.7 \\
\hline Self-stigma & 104 & 32.6 \\
\hline No stigma & 60 & 18.7 \\
\hline
\end{tabular}

Average CD4 level of the last three consecutive visits (in cells $/ \mathrm{m}^{3}$ )

Below 100

100-500

\begin{tabular}{l|l}
32 & 10
\end{tabular}

501-1000

$88 \quad 27.5$

Above 1000

$154 \quad 48$

Use of treatments other than HAART

\begin{tabular}{|l|l|l|}
\hline Traditional medicine & 60 & 18.7
\end{tabular}

\begin{tabular}{l|l|l} 
Religious methods & 166 & 52
\end{tabular}

\begin{tabular}{l|l|l} 
Only HAART & 94 & 29.3
\end{tabular}

Knowledge on adverse effects of ARV drugs

\begin{tabular}{|l|l|l|}
\hline I know & 50 & 15.6
\end{tabular}

\begin{tabular}{l|l|l} 
I don't know & 270 & 84.4
\end{tabular}

Level of adherence

\begin{tabular}{l|l|l} 
MMAS $^{*}<3$ (poor) & 102 & 32
\end{tabular}

\begin{tabular}{l|l|l} 
MMAS $\geq 3$ (good) & 218 & 68
\end{tabular}

Perception towards effectiveness of HAART

\begin{tabular}{l|l|l} 
Effective & 212 & 66.2 \\
Ineffective & 38 & 11.8 \\
Not sure & 70 & 22
\end{tabular}

"Morisky Medication Adherence Score. 
Table 3: Distribution of comorbidities among HIV patients at Dubbo St. Marry Hospital, Southern Ethiopia, 2016 ( $N=320)$.

\begin{tabular}{|l|l|l|}
\hline Other disease conditions & Frequency & Percent \\
\hline Comorbid conditions & & \\
\hline Yes & 182 & 54.5 \\
\hline No & 138 & 45.5 \\
\hline Tuberculosis & 52 & 28.5 \\
\hline Fungal infections & 38 & 21 \\
\hline Depression & 32 & 17.5 \\
\hline Heart failure & 28 & 15.4 \\
\hline UTI & 20 & 11 \\
\hline Others & 12 & 6.6 \\
\hline
\end{tabular}

Table 4: Medication related variables of HIVIAIDS patients at Dubbo St. Marry Hospital, Southern Ethiopia, 2016, $(\mathrm{N}=320)$.

\begin{tabular}{|c|c|c|}
\hline Variables & Frequency & Percent \\
\hline \multicolumn{3}{|c|}{ Types of $1^{\text {st }}$ line ART regimens $(N=254)$} \\
\hline$A Z T+3 T C+E F Z$ & 70 & 27.5 \\
\hline$A Z T+3 T C+N V P$ & 20 & 8 \\
\hline$T D F+3 T C+E F Z$ & 102 & 40.2 \\
\hline TDF + 3TC + NVP & 40 & 15.7 \\
\hline$A B C+3 T C+A Z T$ & 22 & 8.6 \\
\hline \multicolumn{3}{|c|}{ Types of $2^{\text {nd }}$ line ART regimens $(N=66)$} \\
\hline$A Z T+3 T C+L P V / r$ & 28 & 42.4 \\
\hline$A Z T+A B C+L P V / r$ & 22 & 33.3 \\
\hline$T D F+3 T C+L P V / r$ & 16 & 24.3 \\
\hline \multicolumn{3}{|c|}{ Number of pills taken per day } \\
\hline Less than three & 112 & 35 \\
\hline Three-five & 126 & 39.4 \\
\hline More than five drugs & 82 & 25.6 \\
\hline \multicolumn{3}{|c|}{ Frequency of doses per day } \\
\hline Once & 80 & 25 \\
\hline 2 times & 144 & 45 \\
\hline 3 times & 48 & 15 \\
\hline More than 3 times & 48 & 15 \\
\hline \multicolumn{3}{|c|}{ Other concurrent medications } \\
\hline Anti TB drugs & 52 & 16.2 \\
\hline $\mathrm{CPT}^{*}$ & 192 & 60 \\
\hline CV drugs & 30 & 9.4 \\
\hline Contraceptives & 36 & 11.2 \\
\hline Others & 10 & 3.2 \\
\hline
\end{tabular}

${ }^{*}$ Cotrimoxazole prophylactic therapy.

ing $T D F+3 T C+E F Z$ among a first line regimens. The most commonly used concurrent medications were CPT 192 (60\%) followed by anti-TB drugs 52 (16.2\%). It was found that the quarter (25.6\%) of HIV/AIDs patients at Dubbo St. Marry Hospital were taking more than five drugs per day (poly-pharmacy) and about half (45\%) of the respondents responded that they were taking their medications in BID bases (Table 4).

\section{Predictors of poor medication adherence among ART patients}

Bivariate analysis showed that there was significant association between medication adherence and age range of 21-30 years, illiteracy, monthly income, duration ART, self-stigma, comorbidity, living condition, substance use, male gender, number daily doses, types of
ARV drug regimens, occupational status, daily dose, and previous history of hospitalization. Multivariable logistic regression analysis was done to identify independent predictors of medication adherence among the study participants. Accordingly, it was found that presence of comorbidity, substance abuse, living alone, AZT based drug regimen, experiencing self-stigma and number of pills per day independently predicted the likelihood of poor medication adherence among HIV/AIDS patients. Subjects living with diseases other than HIV/AIDS were found to be four times more likely to have poor medication adherence than those without comorbidity $[A O R=4.004,95 \% \mathrm{Cl}=2.104,10.830]$ with $\mathrm{p}$-value = 000 . Using substances like alcohol doubled the likelihood of poor adherence among patients [AOR $=2.360$, $95 \% \mathrm{Cl}=4.347,17.915]$ at $p$-value of 0.020 . Similarly, patients living alone, and taking AZT + 3TC + EFZ based regimen were found to be less likely adherent to their medication $[A O R=0.262,95 \% \mathrm{Cl}=0.083,0.521]$, and [AOR $=0.112,95 \% \mathrm{Cl}=0.067,0.302]$ respectively. It was also found that patients experiencing self-stigma were about three times more likely to have poor medication adherence as compared to those who did not $[A O R=$ $2.922,95 \% \mathrm{Cl}=2.446-10.901]$ at $\mathrm{p}$-value $<0.05$. But, respondents with previous history of hospitalization while on ART were found to have better adherence to their medications than those who have not been hospitalized $[A O R=0.511,95 \% \mathrm{Cl}=0.203,0.885]$ at $\mathrm{p}$-value $<0.05$.

Finally, the study has found that taking more than five drugs per day has increased the likelihood of poor medication adherence for about four times among ART patients at Dubbo St. Marry Hospital [AOR $=4.022,95 \%$ $\mathrm{Cl}=1.665,9.730]$ at $\mathrm{p}$-value $=000$ (Table 5) .

\section{Discussion}

Unlike other chronic conditions, very high levels of adherence (>95\%) are required for ART to be effective for long term and to prevent the emergence of resistant viral strains. Poor adherence to ART can cause drug resistance, higher mortality rates, lower rates of increase in CD4 cell count, lower rates of undetectable viral load, lower therapeutic success, emergence of Ols and increased hospitalization $[5,6]$.

As literatures revealed, it is difficult to measure adherence in the outpatient setting with absolute precision and accuracy as it may result in recall biases due to its dependence on patients' self-report. Therefore, researchers use variety of adherence assessment methods of which none is considered to be a gold standard. The current study used a validated Morisky Medication Adherence assessment method with the aim of assessing level of adherence and predictors of poor adherence among HIV/AIDS patients receiving Antiretroviral Therapy at Dubbo St. Marry Hospital.

Socio-demographically, out of 320 HIV/AIDS patients included in the study, $67 \%$ of were females and those 
Table 5: Predictors of poor medication adherence among patients on ART at Dubbo St. Marry Hospital, Southern Ethiopia, 2016 $(\mathrm{N}=334)$.

\begin{tabular}{|c|c|c|c|c|c|}
\hline \multirow[t]{2}{*}{ Predictors } & \multicolumn{2}{|c|}{ Medication adherence } & \multirow[t]{2}{*}{ COR } & \multirow[t]{2}{*}{ AOR [95\% C.I.] } & \multirow[t]{2}{*}{ p-values } \\
\hline & Poor (\%) & Good (\%) & & & \\
\hline \multicolumn{6}{|l|}{ Comorbidity } \\
\hline Yes & $82(25.6) 2$ & $100(31.2)$ & 1.062 & 4.004 [2.104-10.830] & $0.000^{*}$ \\
\hline No (Ref) & $0(6.2)$ & $118(37)$ & & 1 & \\
\hline \multicolumn{6}{|l|}{ Gender } \\
\hline Female (Ref) & $62(19.4)$ & $152(47.5)$ & & 1 & \\
\hline Male & $80(12.5)$ & $66(20.6)$ & 2.150 & 2.377 [0.041-11.553] & 0.071 \\
\hline \multicolumn{6}{|l|}{ Substance use } \\
\hline Yes & $80(40.3) 2$ & $58(12)$ & 4.822 & 2.360 [4.347-17.915] & $0.020^{*}$ \\
\hline No (Ref) & $2(19)$ & $160(29)$ & & 1 & \\
\hline \multicolumn{6}{|l|}{ Living condition } \\
\hline With family (Ref) & $38(11.8)$ & $82(25.6)$ & & 1 & \\
\hline Alone & $24(7.5)$ & $104(32.5)$ & 0.146 & $2.262[1.083-5.521]$ & $0.007^{*}$ \\
\hline College/university & $20(6.25)$ & $12(3.75)$ & 1.28 & $1.002[0.155-3.671]$ & 0.171 \\
\hline Support centers & $12(3.75)$ & $6(1.8)$ & 2.401 & $0.580[0.966-7.114]$ & 0.403 \\
\hline Other & $8(2.5)$ & $14(4.3)$ & 1.144 & $0.279[0.922-18.006]$ & 0.201 \\
\hline \multicolumn{6}{|l|}{ Types of regimen } \\
\hline TDF + 3TC + EFZ (Ref) & $24(34.4)$ & $78(21.8)$ & & 1 & \\
\hline$A Z T+3 T C+E F Z$ & $18(5.6)$ & $52(19.4)$ & 1.655 & 3.112 [2.767-14.302] & $0.016^{*}$ \\
\hline$A Z T+3 T C+N V P$ & $6(1.8)$ & $14(4.3)$ & 3.441 & 0.409 [0.833-6.685] & 0.800 \\
\hline TDF + 3TC + NVP & $20(6.2)$ & $20(6.2)$ & 2.118 & 5.022 [0.437-5.292] & 0.301 \\
\hline$A B C+3 T C+A Z T$ & $8(2.5)$ & $14(4.3)$ & 0.993 & $1.006[6.022-23.114]$ & 1.351 \\
\hline$A Z T+3 T C+L P V / r$ & $10(3.1)$ & $18(5.6)$ & 1.001 & 2.112 [0.277-1.887] & 0.707 \\
\hline$A Z T+A B C+L P V / r$ & $12(3.75)$ & $10(3.1)$ & 4.055 & 3.950 [1.331-11.261] & $0.023^{*}$ \\
\hline$T D F+3 T C+L P V / r$ & $6(1.8)$ & $10(3.1)$ & 5.108 & $1.093[2.744-22.114]$ & \\
\hline \multicolumn{6}{|l|}{ History of hospitalization } \\
\hline Yes & $32(10)$ & $72(22.5)$ & & $0.511[0.203-0.885]$ & $0.011^{*}$ \\
\hline No (Ref) & $150(46.8)$ & $66(20.6)$ & 1.011 & 1 & \\
\hline \multicolumn{6}{|l|}{ Experiencing stigma } \\
\hline From others & $56(17.5)$ & $100(31.2)$ & 1.403 & 1.772 [0.698-17.229] & 0.201 \\
\hline Self-stigma & $64(20)$ & $40(12.5)$ & 5.884 & $2.922[2.446-10.901]$ & $0.004^{*}$ \\
\hline No stigma (Ref) & $36(11.2)$ & $24(7.5)$ & & 1 & \\
\hline \multicolumn{6}{|l|}{ Number of pills/day } \\
\hline Less than three (Ref) & $52(16.2)$ & $60(18.7)$ & & 1 & \\
\hline Three-five & $72(22.5)$ & $54(16.8)$ & 1.667 & 1.003 [2.119-65.002] & 0.089 \\
\hline More than five drugs & $24(7.5)$ & $58(18.3)$ & 4.710 & $4.022[1.665-9.730]$ & $0.000^{*}$ \\
\hline
\end{tabular}

"Statistically significant.

found within the age range of mid-thirties to mid-forties (50.6\%). This is consistent with N.C Talam, et al. study in Kenya [10]. This is a clear indication that the disease affects a productive segment of the population in the country.

This study has found that level of medication adherence among ART patients at Dubbo St. Marry hospital was $60 \%$. This is consistent with myriad of studies conducted in most developed countries which documented that HAART adherence rates range from $40 \%$ to $75 \%$. This finding is higher than N.C Talam, et al. study in Kenya [10], which showed that $43.2 \%$ of respondents adhered to their medication. But, it is lower than the study done in north-west Ethiopia which shows that the adherence level of patients was $80.9 \%$ [11]. The discrep- ancy of findings could partly be explained as the difference in methods used to assess adherence, income and difference in health care facility.

The most common reasons reported for poor adherence were simple forgetting to take medications (43\%), fear of adverse effects (29\%) followed by feeling hopelessness. This finding is in agreement with several studies conducted previously [12-14]. As corroborated by many past studies too majority of ART patients report forgetting as the most common reason for their poor adherence. This could be due to the effect of the disease on thinking ability of the patients or resultant depression.

In the current study, $84.4 \%$ of ART patients reported that they do not know adverse effects resulted from 
ARV drugs. This could have a contribution to poor adherence as fear of toxicity for the drugs was found to be the second common reason of non-adherence especially AZT based drug regimens were found to be significantly associated with poor adherence.

Poor medication adherence among patients with comorbidity and those taking more than five pills per day was a fourfold in the current study. Similarly, use of substances, loneness, AZT based regimen, and self-stigma independently predicted poor medication adherence. This finding has consistency with study done in Australia which showed that alcohol consumption has significantly been associated with poor adherence [15]. Sankar, et al. also found that loneliness is a key factor that influence adherence to ART [16].

Similarly, many other authors reported that the existence of significant relationships between several factors, non-adherence to combination therapy can result from forgetting, lack of motivation, and intolerance of side effects. As reported in the study conducted in southwest Ethiopia at the ART unit of Jimma University specialized hospital, depression was associated with non-adherence. Adherence was common among those who had social support systems. More than $75 \%$ of the respondents reported that they missed doses due to forgetting, feeling sick or ill, being busy, and running out of medications. A study conducted in the southern part of Ethiopia at Yirgalem Hospital found that the main reasons for non-adherence included being busy or simply forgetting, changes in daily routine, and being away from home [17].

In this study, there was no association between variables like gender, marital status, age and income which were found to be predictors of poor adherence in previous studies. The reason could be difference in adherence assessment methods, study design, socio-demography of the population etc.

However, patients with previous history of hospitalization while on ART were found to be more adherent to their medication as compared to others. The reason might be partly explained as further investigation and assessment of patients' condition and adherence status by physicians, increased awareness about medication adherence and change in attitude they got from health professionals at the time of hospitalization could result in improved medication taking behaviors.

\section{Limitations of the Study}

Chance of recall bias in adherence assessment as it was based on respondents' self-report, absence of causality assessment for ADR, chart review may result in missing of some data.

\section{Conclusions}

Level of adherence (68\%) among patients on ART at Dubbo St. Marry hospital was found to be suboptimal but comparable to other developing countries. Forgetting and fear of side effects were commonly reported as reasons for non-adherence. Statistically, poly-pharmacy, living alone, feeling self-stigma, AZT-based drug regimen and comorbidity independently predicted poor adherence.

\section{Recommendations}

Based on the above findings, the following recommendations are forwarded:

- Strategies should be designed to enhance patients' awareness regarding ways to improve adherence, adverse effects and effectiveness of HAART.

- Refreshment trainings and clinical updates should be provided to heath care providers.

- Continuous community health education programs should be provided to avoid stigma and increasing social support to PLWHA.

\section{Competing Interests}

None declared.

\section{Acknowledgement}

The author is grateful to W/ro Birtukan Ermias, Blen Hailu and Grace Hailu, for their unreserved support throughout the study. Finally, Dubbo St. Marry hospital staffs and the study participants are also acknowledged for their cooperation during data collection.

\section{References}

1. United Nations Program on HIVIAIDS (2009) AIDS Epidemic Update. UNAIDS/09.36E/JC1700E.

2. The Federal Democratic Republic of Ethiopia (2005) Guidelines for the implementation of antiretroviral therapy in Ethiopia. Addis Ababa, Ethiopia.

3. Ministry of Health (2007) Disease Prevention and Control Department, Single Point HIV Prevalence Estimate. 3: S123-S127.

4. Foreman M (2006) Antiretroviral drugs for all? Obstacles to access to HIVIAIDS treatment. Lessons from Ethiopia, Haiti, India, Nepal and Zambia. Panos Global AIDS Program.

5. Hogan D, Salomon J (2005) Prevention and treatment of HIVIAIDS in resource limited settings. Bulletin of WHOM 83: 2.

6. Paterson DL, Swindells S, Mohr J, Brester M, Vergis E, et al. (2000) Adherence to protease inhibitor therapy and outcomes in patients with HIV infection. Ann Intern Med 133: 21-30.

7. Carballo E, Suarez CC, Carrera I, Fraga J, de la Fuente J, et al. (2004) Assessing relationships between health-related quality of life and adherence to antiretroviral therapy. Qual Life Res 13: 587-599.

8. Tadios Y, Davey G (2006) Retroviral drug adherence and its correlates in Addis Ababa, Ethiopia. Ethiop Med $\mathrm{J} 44$ : 237-244.

9. Morisky DE, Green LW, Levine DM (1986) Concurrent and predictive validity of a self-reported measure of medication adherence. Med Care 24: 67-74. 
10. NC Talam, P Gatongi, J Rotich, S Kimaiyo (2008) Factors affecting ntiretroviral drug adherence among hiv/aids adult patients attending hiv/aids clinic at moi teaching and referral hospital, eldoret, kenya. East Afr J Public Health 5: 74-78.

11. Tsega B, Srikanth BA, Shewamene Z (2015) Determinants of non-adherence to antiretroviral therapy in adult hospitalized patients, Northwest Ethiopia. Patient Prefer Adherence 9: 373-380.

12. World Health Organization (2006) From access to adherence: The challenges of antiretroviral treatment- Studies from Botswana, Tanzania and Uganda. Geneva.

13. Wroth TH, Pathman DE (2006) Primary medication adherence in a rural population: The role of the patient-physician relationship and satisfaction with care. J Am Board Fam Med 19: 478-486.
14. Simpson RJ (2006) Challenges for improving medicine adherence. Journal of the American Medical Association 296.

15. Mc Allister J (2006) Antiretroviral drug therapy for HIV-Infection: Developing an adherence framework. Management HIV, Sydney, Australia.

16. Sankar A, Golin C, Simoni JM, Luborsky M, Pearson C (2006) How qualitative methods contribute to understanding combination antiretroviral therapy adherence. J Acquir Immune Defic Syndr 43: S54-S68.

17. Endrias Markos, Alemayehu Worku, Gail Davey (2008) Adherence to ART in PLWHA at Yirgalem Hospital, South Ethiopia. Ethiopian Journal of Health Development 20: 234238. 